\title{
Swivel and Roll! - A new dance for the modern Thoracic Surgeon
}

Sparsh Prasher ${ }^{*}$, Michael Klimatsidas

From World Society of Cardiothoracic Surgeons 25th Anniversary Congress, Edinburgh

Edinburgh, UK. 19-22 September 2015

\section{Background/Introduction}

In comparison to open surgery, VATS lung resections are technically challenging operations as the operative field is transformed from a three dimensional multiangle wide view to a two dimensional screen. Therefore careful pre-operative and intra-operative planning is required to complete the procedure safely and successfully. All our patients undergo a Computed Tomography (CT) which is essential for pre-operative planning.

The Multiplanar Reconstruction (MPR) mode displays images in the Coronal and Sagittal view. The sagittal view can be rotated by 90 degrees to bring the lung
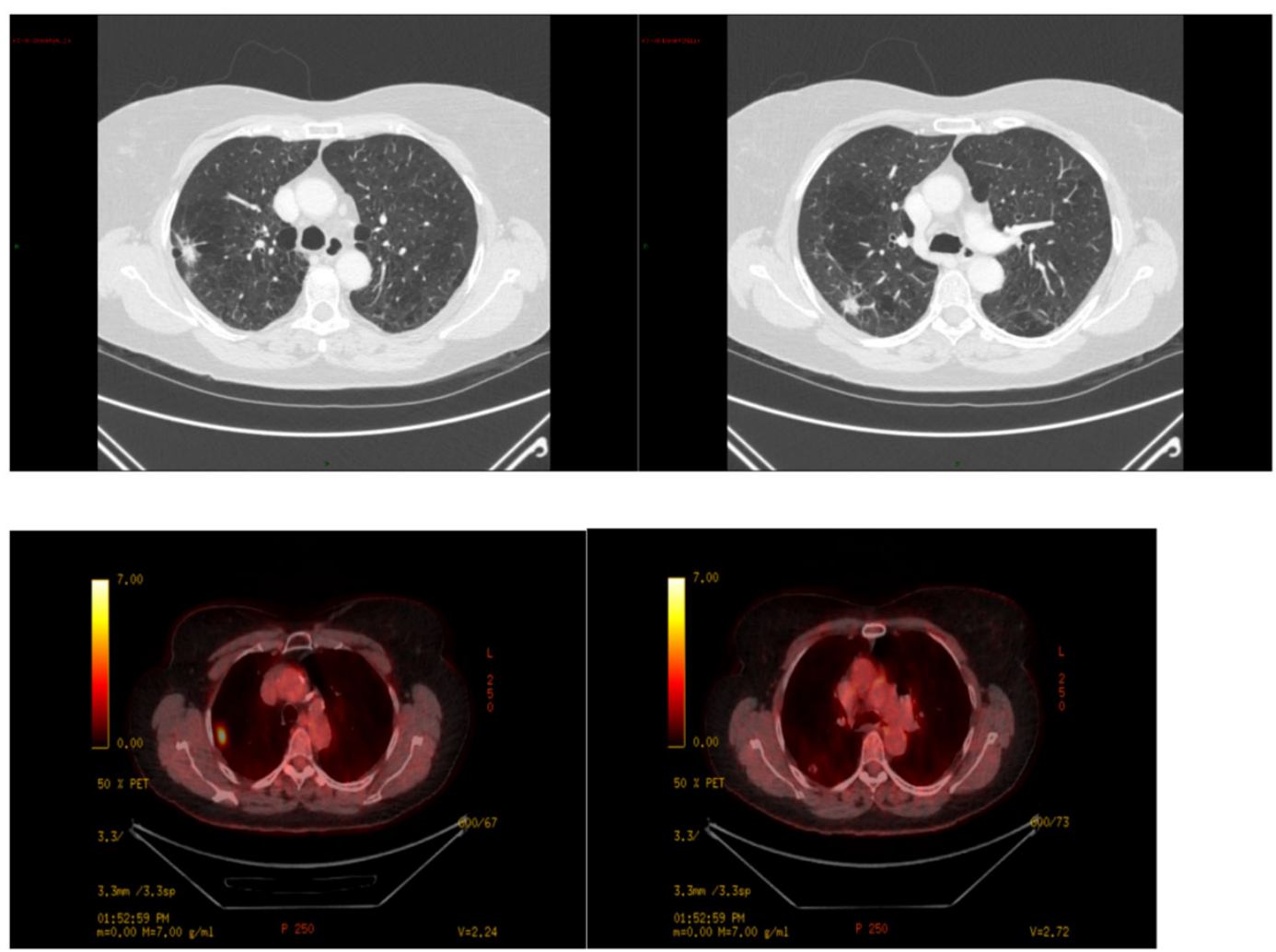

Figure 1 Two Right sided lung lesions. But only one is FDG Avid on the PET scan.

Golden Jubilee National Hospital, Agamemnon St, Clydebank, Dunbartonshire G81 4DY, UK 


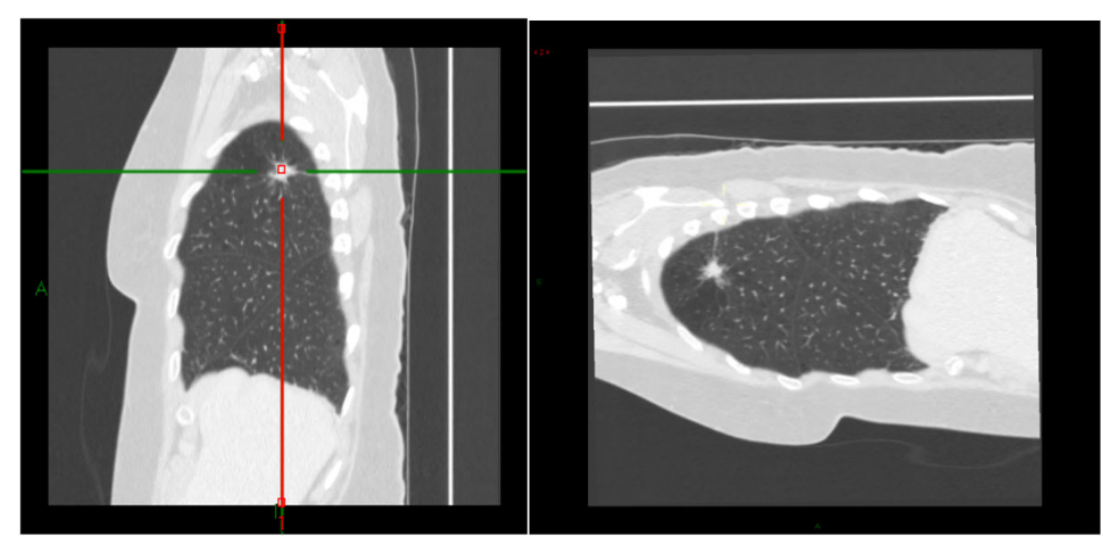

Figure 2 Pre Swivel orientation in MPR mode. Note that in the sagittal view the Spine is on the right side and sternum on the left. The Right upper lobe is on the left of the screen but on the right of the surgeon.

apex to the left side. This corresponds to the patient's position in the right lateral decubitus position (for left sided resections) but not in the left lateral decubitus position for right sided resections. Therefore, the standard sagittal view in the MPR mode is not adequate for operative planning for right sided lung resections.

\section{Aims/Objectives}

To improve pre-operative planning for VATS lung resections by introducing a new way of manipulating the $\mathrm{CT}$ images.

\section{Method}

We used the Swivel function to manipulate the images in the coronal axis to produce a sagittal view so that the spine lies on the left hand side and the sternum on the right side. The roll function allows the image in the sagittal view to move by 90 degrees this orientates the images in the patient's position on the operating table.

\section{Results}

The results are demonstrated in the images below.

Published: 16 December 2015

doi:10.1186/1749-8090-10-S1-A203

Cite this article as: Prasher and Klimatsidas: Swivel and Roll! - A new

dance for the modern Thoracic Surgeon. Journal of Cardiothoracic Surgery 2015 10(Suppl 1):A203.

\section{Submit your next manuscript to BioMed Central} and take full advantage of:

- Convenient online submission

- Thorough peer review

- No space constraints or color figure charges

- Immediate publication on acceptance

- Inclusion in PubMed, CAS, Scopus and Google Scholar

- Research which is freely available for redistribution 